\section{SIFAT MEKANIK BETON SERAT IJUK YANG TERENDAM AIR LAUT}

\author{
Chaeril Anwar', Erniati Bachtiar ${ }^{2 *}$, Nur Khaerat Nur ${ }^{3}$ \\ Universitas Fajar, Makassar ${ }^{1,2,3}$
}

Email: erni@unifa.ac.id ${ }^{2}$

Abstrak. Paper ini bertujuan untuk membahas sifat mekanik (kuat lentur, kuat tarik belah dan kuat tekan) pada beton serat ijuk yang terendam air laut dan untuk mengetahui panjang serat ijuk yang optimum untuk beton serat ijuk yang terendam air laut. Metode yang dilakukan adalah metode eksperimental yang dilakukan di laboratorium, sampel beton dibuat dengan 4 variasi panjang serat ijuk mulai dari $25 \mathrm{~mm}, 50$ $\mathrm{mm}$, dan 75, serta $100 \mathrm{~mm}$ dengan penambahan serat sebanyak 4\%. Hasil penelitian tantang beton serat ijuk bahwa semakin panjang serat ijuk yang digunakan pada beton maka sifat mekaniknya semakin menurun. Beton serat yang terendam air laut lebih tinggi nilai sifat mekaniknya dibandingkan beton normal Panjang serat ijuk yang optimum pada beton serat dari hasil penelitian ini adalah $25 \mathrm{~mm}$.

Kata Kunci: Beton, serat, Air Laut, ljuk, Sifat Mekanik

\section{INDONESIAN JOURNAL OF FUNDAMENTAL SCIENCES (IJFS)}

\section{E-ISSN: 2621-6728 \\ P-ISSN: 2621-671X}

Submitted: June $27^{\text {th }}, 2019$

Accepted : August, $29^{\text {th }}, 2019$

Abstract. This research aims to determine the value of mechanical properties in fiber fibers which are submerged in seawater and to find out the optimum length of fiber fibers to the mechanical properties of fiber fibers which are submerged in sea water. The method used is an experimental method carried out in the laboratory by varying the length of the fibers, which is $25 \mathrm{~mm} ; 50 \mathrm{~mm}$; $75 \mathrm{~mm}$; and $100 \mathrm{~mm}$ with 4\% fiber addition. Tests of mechanical properties carried out in the form of compressive strength, split tensile strength, and flexural strength. The results of the research challenge the palm fiber-concrete that the longer the fibers used in the concrete, the mechanical properties decrease. Fiber concrete submerged in seawater has higher mechanical properties than normal concrete. Optimum fiber length length in fiber concrete from the results of this study is $25 \mathrm{~mm}$. 


\section{LATAR BELAKANG}

Indonesia merupakan merupakan negara kepulauan sehingga potensi bangunan konstruksi terendam/terkena air laut pada bangunan beton yang berada dipesisir sangat besar. Indonesia merupakan negara kepulauan sehingga Indonesia memiliki sangat banyak bangunan/konstruksi yang selalu terendam atau terkena pengaruh air laut. Adapun kandungan air laut terdiri dari natrium (31\%), magnesium (4\%), klorida (55\%), sulfat ( $8 \%$ ), potasium ( $1 \%)$, dan kalsium ( $1 \%)$, serta sisanya sekitar $1 \%$ yang berupa florida, bikarbonat, strontium, asam borak dan bromida. Beton yang terendam air laut atau terkena air laut memberikan efek pada kekuatan dan keawetan beton. Kandungan garam air laut sangat tinggi yang memiliki sifat agresif yang dapat masuk kepori-pori beton yang mengakibatkan terjadi korosi beton yang dikenal hilangnya sebagian massa beton dan lambat laun terjadi korosi pada tulangan beton. Hilangnya atau berukurangnya kekuatan dan kekakuan beton dapat mempercepat proses korosi pada beton (Hidayat, 2011).

Pembangunan infrastruktur yang menggunakan material beton semakin meningkat. Seiring dengan kebutuhan material beton semakin tinggi, maka kinerja dan sifat dari material beton perlu diperbaiki karena salah satu kelemahan dari beton adalah kuat tarik yang sangat kecil dan getas. Penambahan serat merupakan salah satu cara menaikkan kuat tarik beton. Serat (fiber) yang ditambahkan pada beton dapat menggunakan serat alam maupun non alami. Serat non alami yang sering digunakan adalah serat baja, karbon, serat plastik, serat fiberglass. Penelitian tentang serat alami yang biasanya menggunakan serat dari tumbuhan/tanaman seperti serat tandan kosong kelapa sawit, serat ijuk, serat bambu dapat menaikkan kuat tarik dari beton (Mudji Suhardiman, 2011, Mikael Wora \& Fransiskus Xaverius Ndale, 2018). Serat yang ditambhakan pada adukan beton dimkasudkan agar dapat menaikkan kuat tarik/lentur pada beton, sebagaimana kita ketahui bahwa beton memiliki kuat tarik yang cukup rendah. Nilai kuat lentur/tarik beton yang sangat kecil berefek pada beton yaitu beton sangat mudah retak sehingga mengurangi durabilitas (keawetan) beton (Tjokrodimuljo, 1996). Campuran yang dibuat dari semen hidrolik, agregat (kasar/halus), dan bahan tambah lainnya yang memperkuat berupa serat-serat disebut beton serat ( $A C I$ 544.1R-96). Serat yang cocok untuk memperkuat beton telah diproduksi dari baja, kaca, dan polimer organik (serat-serat sintetis).

Darul, dkk (2014) telah mengkaji beton K-175 dengan menambhakan serat ijuk, dengan hasil bahwa kuat tarik belah beton maksimum dicapai dengan menggunakan $2 \%$ serat ijuk. Beton yang ditambahkan serat ijuk dapat meningkatkan kualitas beton. Dalam hal ini perlu dilakukan kajian lebih lanjut untuk mengetahui pengaruh serat ijuk pada beton dengan jumlah serat iijuk lebih dari $2 \%$. Doni Hermanto, dkk (2014), melakukan penelitian tentang batako yang ditambahkan bahan tambah serat ijuk, dengan hasil bahwa jumlah optimum penggunaan serat ijuk pada beton sebesar 3,302\%.

Mohamed A. Ismail dan Huzaifah Bin Hasyim (2008) telah meneliti tentang pengembangan kekuatan beton menggunakan serat kelapa sawit. Panjang serat yang divariasikan adalah $1 \mathrm{~cm}, 3 \mathrm{~cm}$ dan $5 \mathrm{~cm}$ derngan menggunakan dua persentase serat yaitu $0,25 \%$ dan $0,50 \%$ dari berat semen, masin-masing. Hasil pengujian 
menujukkan penambahan serat 0,25\% dan 0,50\% diperoleh panjang serat optimum untuk kedua peresentase tersebut adalah $5 \mathrm{~mm}$. Panjang serat optimum ini berdasarkan pengujian dengan peningkatan kekuatan yang dihasilkan sebesar $39 \%$ dibandingkan dengan sampel OPC.

Di Indonesia terdapat banyak Pohon enau (arenga pinnata). Pelepah enau terdapat serat yang diberi nama serat ijuk yang berbentuk seperti benang yang berwarna hitam dan berwarna kemerahan pada ujung serat. Pemanfaatan serat ijuk pada genteng beton dapat memperbaiki fisik dan mekanik pada genteng beton. Sifat serat ijuk memiliki massa jenis sebesar 1,136 gram/cm3, kandungan kimia berupa selulosa 51,5\%, hemiselulosa 15,9\%, kadar air 8,9\%, lignin 43,1\% dan abu 2,5\% (Christiani S. Evi, 2008). Serat ijuk meningkatkan kekuatan lentur dan mengurangi sifat getasnya beton (Randing, 1995). Pemanfaatan ijuk pada panel dinding dan genteng dapat terhindar dari patah kejut pada saat mengalami pembebanan (Yuwono S, 1994). Sifat mekanis beton dapat diperbaiki dengan menambahkan serat diantaranya dapat meperbaiki ketahanan kejut, kuat lentur, kuat tarik, kuat tekan dan keuletan pada beton (Neville dan Brooks, 2010).

Penelitian ini membahas tentang sifat mekanik pada beton serat ijuk yang direndam air laut. Sifat mekanik yang dikaji dalam paper ini adalah kekuatan pada beton serat ijuk yang terendam air laut. Disamping itu, kuat tekan pada beton normal dan beton serat yang terendam air laut tetap ditinjau sebagai nilai acuan dari nilai kuat tarik belah dan kuat lentur.

\section{METODE PENELITIAN}

Penelitian ini menggunakan metode eksperimental. Pembuatan sampel beton dilaksanakan di Laboratorium Struktur dan Bahan, Prodi Teknik Sipil, Fakultas Teknik, Universitas Fajar, Makassar. Ada beberapa material yang digunakan dalam penelitian ini terdiri dari beberapa material yakni semen type PCC (Portland Composite Cement), agregat kasar, agregat halus dan serat ijuk serta air. Agregat yang digunakan adalah agregat lokal. Pengujian karakteristik agregat dilakukan berdasarkan standar SNI. Karakteristik agregat halus diperlihatkan pada Tabel 1 dan agregat kasar ditunjukkan pada Tabel 2.

Serat ijuk adalah salah satu serat alam yang diperoleh dari pangkal pelepah enau (arenga pinnata). Pohom enau (arenga pinnata) merupakan salah satu tumbuhan bangsa palma. Serat ijuk memiliki sifat awet, tidak mudah busuk, dan kuat. Serat ijuk inilaih yang dimanfaatkan sebagai bahan tambah pada campuran adukan beton. Penambahan serat ijuk yang diberikan pada campuran beton sebanyak $4 \%$ dari berat semennya. Variasi panjang serat terdiri dari 4 variasi yakni 25 $\mathrm{mm} 50 \mathrm{~mm}$, dan $75 \mathrm{~mm}$, serta $100 \mathrm{~mm}$. Serat ijuk yang dipakai berasal dari Kolaka Utara, Sulawesi Tenggara. 
Tabel 1. Karakteristik Material Agregat Halus

\begin{tabular}{clcc}
\hline No. & Jenis Karakteristik dan Hasil Pengujian & Interval \\
\hline 1 & Berat Volume & & \\
& a. Kondisi Lepas & 1,56 & $1,4-1,9 \mathrm{~kg} / \mathrm{liter}$ \\
& b. Kondisi Padat & 1,67 & $1,4-1,9 \mathrm{~kg} / \mathrm{liter}$ \\
2 & Kadar Lumpur & $4,50 \%$ & $0,2 \%-5 \%$ \\
3 & Kadar Air & $3,31 \%$ & $3 \%-5 \%$ \\
4 & Absorpsi & 2,04 & $0,2 \%-4 \%$ \\
5 & Berat Jenis & & \\
& a. Bj. Nyata & 2,74 & $1,60-3,30$ \\
& b. Bj. Dasar Kering & 2,65 & $1,60-3,31$ \\
& c. Bj. Kering permukaan & 2,70 & $1,60-3,32$ \\
6 & Modulus Kehalusan & 3,01 & $2,3-3,1$ \\
7 & Kadar Organik & No.2 & $<\mathrm{No.3}$ \\
\hline
\end{tabular}

Tabel 2. Karakteristik Material Agregat Kasar

\begin{tabular}{clcc}
\hline No & \multicolumn{2}{c}{ Jenis Karakteristik dan Hasil Pengujian } & Interval \\
\hline 1 & Berat Volume & 1,60 & $1,6-1,9 \mathrm{~kg} / \mathrm{liter}$ \\
& a. Kondisi Lepas & 1,74 & $1,6-1,9 \mathrm{~kg} / \mathrm{liter}$ \\
& b. Kondisi Padat & $0,70 \%$ & Maks $1 \%$ \\
2 & Kadar Lumpur & $1,65 \%$ & $0,5 \%-2 \%$ \\
3 & Kadar Air & $1,79 \%$ & Maks 4\% \\
4 & Absorpsi & & \\
5 & Berat Jenis & 3,03 & $1,60-3,33$ \\
& a. Bj. Nyata & 2,87 & $1,60-3,33$ \\
& b. Bj. Dasar Kering & 2,92 & $1,60-3,33$ \\
& c. Bj. Kering Permukaan & 6,63 & $6-7,1$ \\
6 & Modulus Kehalusan & $31 \%$ & Maks 50\% \\
7 & Keausan & & \\
\hline
\end{tabular}

Penelitian ini menggunakan mesin mixer untuk mencampur bahan material penyusun beton. Sampel silinder menggunakan cetakan besi berbentuk silinder yang berdiameter $100 \mathrm{~mm}$ dan tinggi $200 \mathrm{~mm}$. Sampel balok menggunakan cetakan yang berbentuk balok dengan lebar $100 \mathrm{~mm}$ tinggi $120 \mathrm{~mm}$ panjang $600 \mathrm{~mm}$. Pengujian sifat mekanik menggunakan Universal Testing Machine (UTM). Pencampuran beton serat dilakukan setelah pemeriksaan agregat baik kasar maupun halus dilakukan berdasarkan Standar Nasional Indonesia (SNI). Setelah memenuhi syarat material penyusun dilakukan pencampuran dan pemeliharaan beton dilaksanakan di Laboratorium. Hasil mix design campuran beton yang menggunakan metode DOE (Devolopment Of Envoiment) terlihat pada Tabel 3. 
Tabel 3. Komposisi Campuran Beton Serat ljuk (BSI) $\left(\mathrm{kg} / \mathrm{m}^{3}\right)$

\begin{tabular}{cccccc} 
Sampel & Semen & Air & Pasir & Kerikil & Serat ljuk 4\% \\
\hline BSI $25 \mathrm{~mm}$ & 562,50 & 225,00 & 549,475 & 1223,03 & 22,50 \\
BSI $50 \mathrm{~mm}$ & 562,50 & 225,00 & 549,475 & 1223,03 & 22,50 \\
BSI $75 \mathrm{~mm}$ & 562,50 & 225,00 & 549,475 & 1223,03 & 22,50 \\
BSI $100 \mathrm{~mm}$ & 562,50 & 225,00 & 549,475 & 1223,03 & 22,50 \\
\hline
\end{tabular}

BSI $25 \mathrm{~mm}$ : Beton serat ijuk dengan panjang serat $25 \mathrm{~mm}$ BSI $50 \mathrm{~mm}$ : Beton serat ijuk dengan panjang serat $50 \mathrm{~mm}$ BSI $75 \mathrm{~mm}$ : Beton serat ijuk dengan panjang serat $75 \mathrm{~mm}$ BSI $100 \mathrm{~mm}$ : Beton serat ijuk dengan panjang serat $100 \mathrm{~mm}$

Sampel beton serat ijuk dibuat dengan dua bentuk sampel yakni berbentuk silinder dan balok. Silinder berukuran $10 \mathrm{mmx} 20 \mathrm{~mm}$. Balok berukuran $10 \mathrm{~mm}$ x 12 $\mathrm{mm} \times 600 \mathrm{~mm}$. Sampel berbentuk silinder untuk pengujian kuat tekan dan kuat tarik belah, sedangkan benda uji berbentuk balok untuk pengujian kuat lentur. Jumlah sampel dibuat masing-masing 3 buah sampel/variasi. Pembuatan benda uji menggunakan komposisi campuran seperti pada Tabel 3 yang menggunakan molen dalam mencampurkan material. Pada beton segar, nilai slump diukur menggunakan alat Kerucut Abrams yang berukuran tinggi $300 \mathrm{~mm}$, diameter dibawah $200 \mathrm{~mm}$, dan diameter diatas $100 \mathrm{~mm}$ dan dilengkapi dengan tongkat pengerojok berdiameter $16 \mathrm{~mm}$ dan panjangnya $600 \mathrm{~mm}$. Nilai slup diukur sebelum dituang pada cetakan silinder atau balok.

Sebelum sampel beton dilakukan pengujian, maka perlu dilakukan curing beton dengan melakukan perendaman pada sampel yang telah dikeluarkan dari cetakan. Proses curing dilakukan agar proses reaksi hidrasi semen bekerja secara optimal sehingga terhindar dari munculnya retak-retak akibat panas hidrasi yang timbul dan kualitas beton tetap sesuai yang direncanakan. Beton dibiarkan selama 24 sebelum dibuka cetakannya kemudian selanjutnya dilakukan curing beton dengan merendam sampel beton tersebut didalam bak air yang terisi air. Curing dilakukan sampai beton serat berumur 28 hari menggunakan air laut. Beton diberi tanda atau kode sebelum direndam. Setelah beton berumur 27 hari maka beton dikeluarkan dalam bak perendam dan kemudian didiamkan selama 24 jam agar beton pada saat pengujian dalam keadaan kering. Pengujian kuat tekan dan kuat tarik belah serta kuat lentur beton dilakukan pada saat beton berumur 28 hari. Pengujian sifat mekanis berdasarkan standar SNI.

\section{HASIL DAN PEMBAHASAN}

\section{Kuat Tekan Beton Serat ljuk}

Kualitas mutu beton dapat dilihat nilai nilia kuat tekan beton. Kuat tekan beton serat ijuk didapatkan dengan cara menekan beton sampai hancur. Saat beton menerima beban maksimum (Pmaks) dibagi dengan luas permukaan diperoleh nilai kuat tekan. Hasil rata-rata dari 3 sampel nilai kuat tekan beton serat ijuk sebagaimana pada Gambar 1. 


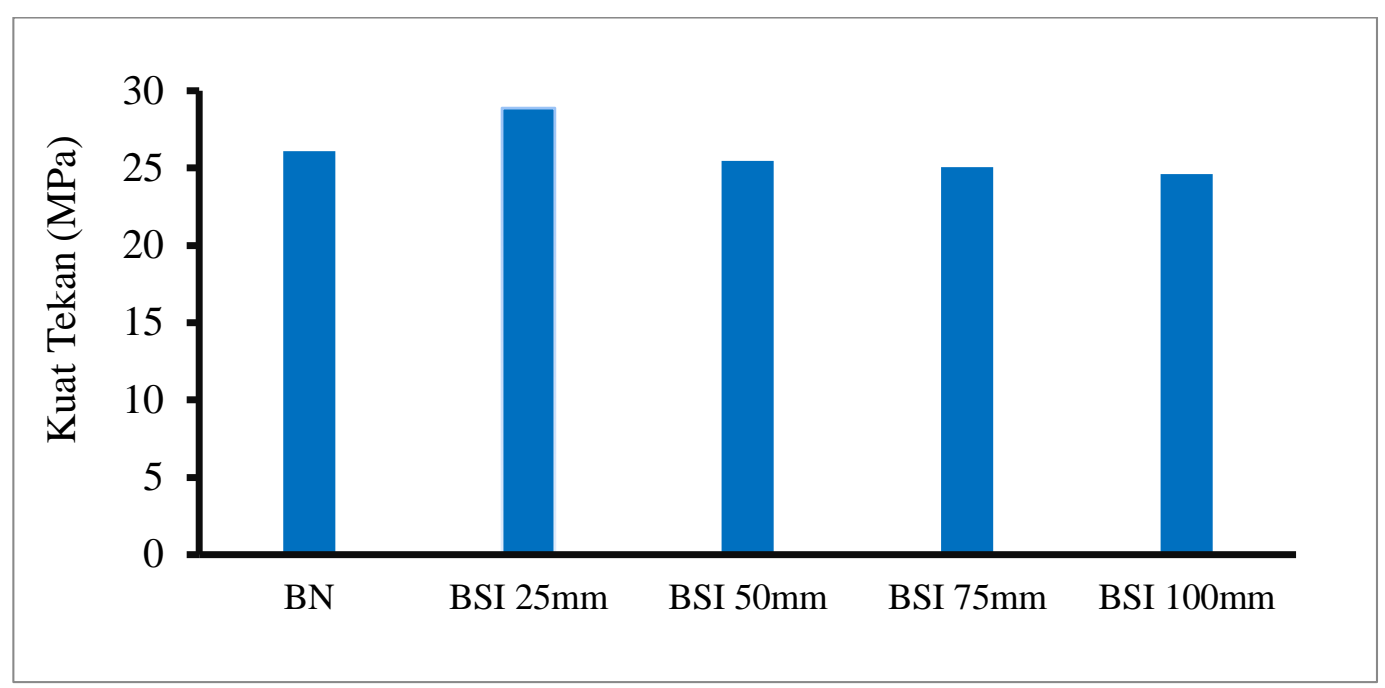

Gambar 1. Nilai Kuat Tekan Beton Serat ljuk

Gambar 1 memperlihatkan variasi panjang serat ijuk dengan kuat tekan beton serat ijuk. Serat ijuk dengan variasi panjang serat $25 \mathrm{~mm}, 50 \mathrm{~mm}, 75 \mathrm{~mm}, 100 \mathrm{~mm}$ diperoleh kuat tekan pada beton berturut-turut sebesar 28,87 MPa ; 25,48 MPa ; 25,05 MPa ; dan 4,63 MPa. Nilai kuat tekan menurun seiring dengan bertambahnya panjang serat yang divariasikan. Hasil kuat tekan tertinggi yang diperoleh yaitu sebesar 28,87 MPa dengan panjang serat $25 \mathrm{~mm}$. Gambar 1 juga memperlihatkan semakin panjang serat maka nilai kuat tekan beton serat menurun. Gambar 1 juga terlihat beton serat $25 \mathrm{~mm}$ yang terendam air laut memiiliki kuat tekan lebih tinggi dibandingkan dengan beton normal. Menurut Mikael Wora dan Fransiskus Xaverius Ndale (2018) bahwa serat ijuk menurunkan kuat tekan dan menaikkan kuat tarik beton.

Gambar 1 terlihat bahwa beton normal memiliki kuat tekan lebih kecil dibandingkan dengan beton serat yang terendam air laut. Kuat tekan beton serat ijuk $25 \mathrm{~mm}$ yang terendam air laut naik sebesar 10,57\% dari beton normal. Sebagaimana penelitian Erniati dkk $(2015,2016)$ telah meneliti beton yang memadat sendiri yang menggunakan air laut sebagai air pencampuran dan sebagai curingnya, dengan hasil bahwa sifat mekanik beton memadat sendiri yang menggunakan curing dan air pencampuran dengan air laut memiliki sifat mekanik lebih tinggi dibandingkan yang menggunakan air tawar.

\section{Kuat Tarik Belah}

Test kuat tarik belah pada beton dimaksudkan untuk menganalisis ketahanan geser suatu struktur. Kuat tarik belah maksimum didapatkan pada saat beban maksimum yang menyebabkan beton terbelah menerima beban tersebut. Hasil ratarata tiga sampel kuat tarik belah beton serat ijuk diperlihatkan pada Gambar 2. 


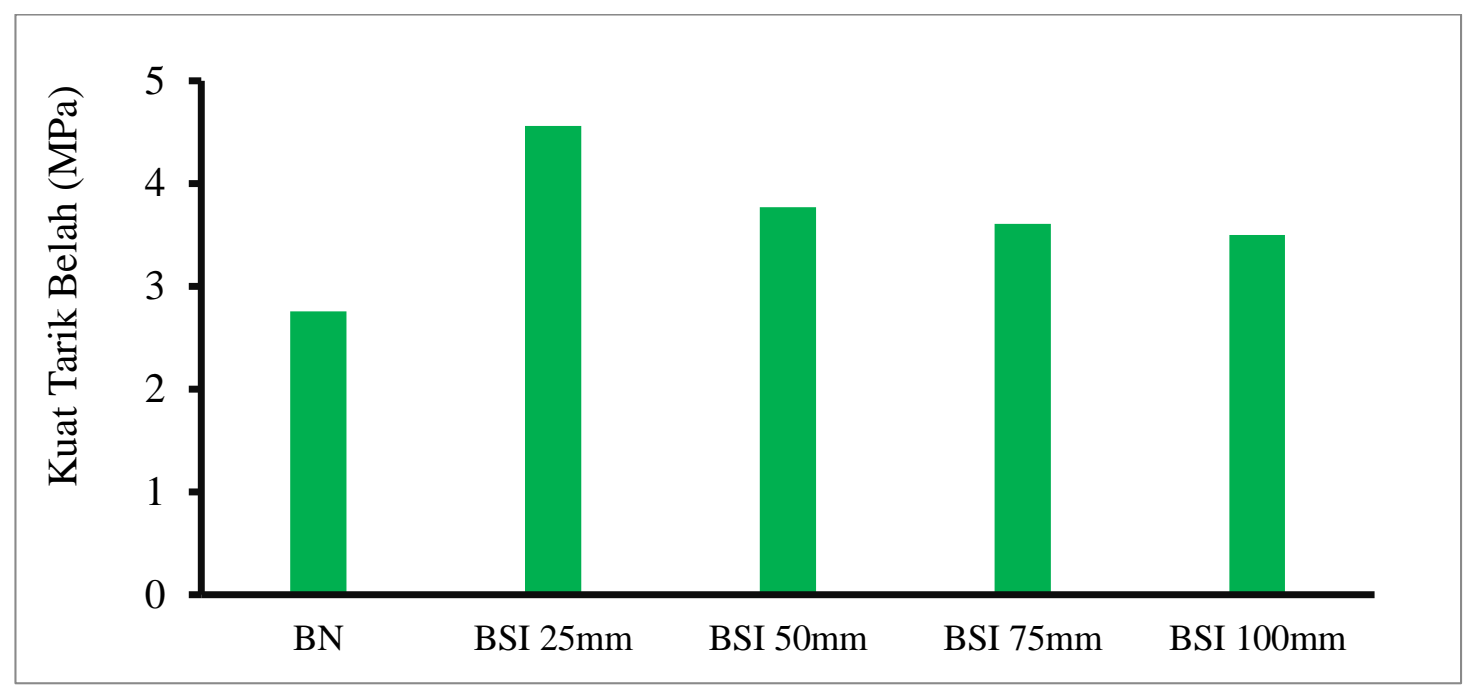

Gambar 2. Kuat Tarik Belah Beton Serat ljuk

Hubungan panjang serat dan kuat tarik belah dapat dilihat pada Gambar 2 . Gambar 2 menunjukan nilai kuat tarik belah yang divariasikan panjang serat ijuk. Beton serat dengan variasi panjang serat $25 \mathrm{~mm}, 50 \mathrm{~mm}, 75 \mathrm{~mm}, 100 \mathrm{~mm}$ diperoleh kuat tarik belah berturut-turut sebesar 4,56 MPa ; 3,77 MPa ; 3,61 MPa ; dan 3,50 MPa. Nilai kuat tarik belah menurun seiring dengan bertambahnya panjang serat yang divariasikan. Hasil kuat tarik belah tertinggi yang diperoleh yaitu sebesar 4,56 MPa dengan panjang serat $25 \mathrm{~mm}$. Kuat tarik belah dengan adanya serat yang ditambhakan pada beton yang terendam air laut dibandingkan dengan beton normal tampa serat dan terendam air tawar. Semakin panjang serat maka semakin rendah kuat tarik belahnya. Nilai kuat tarik belah beton yang dicuring dengan air laut lebih tinggi dibandingkan beton normal yang tanpa serat dan curing air tawar.

\section{Kuat Lentur}

Pengujian kuat lentur digunakan untuk mengevaluasi kemampuan pelat dan balok dalam melawan kegagalan patah. Nilai kuat lentur maksimum didapatkan pada saat beton patah menerima dua beban di dua titik yang telah ditentukan. Dari data yang dihasilkan kuat lentur kemudian diolah berdasarkan SNI 03-4431-2011. Hasil kuat lentur beton serat ijuk dapat dilihat pada Gambar 3. 


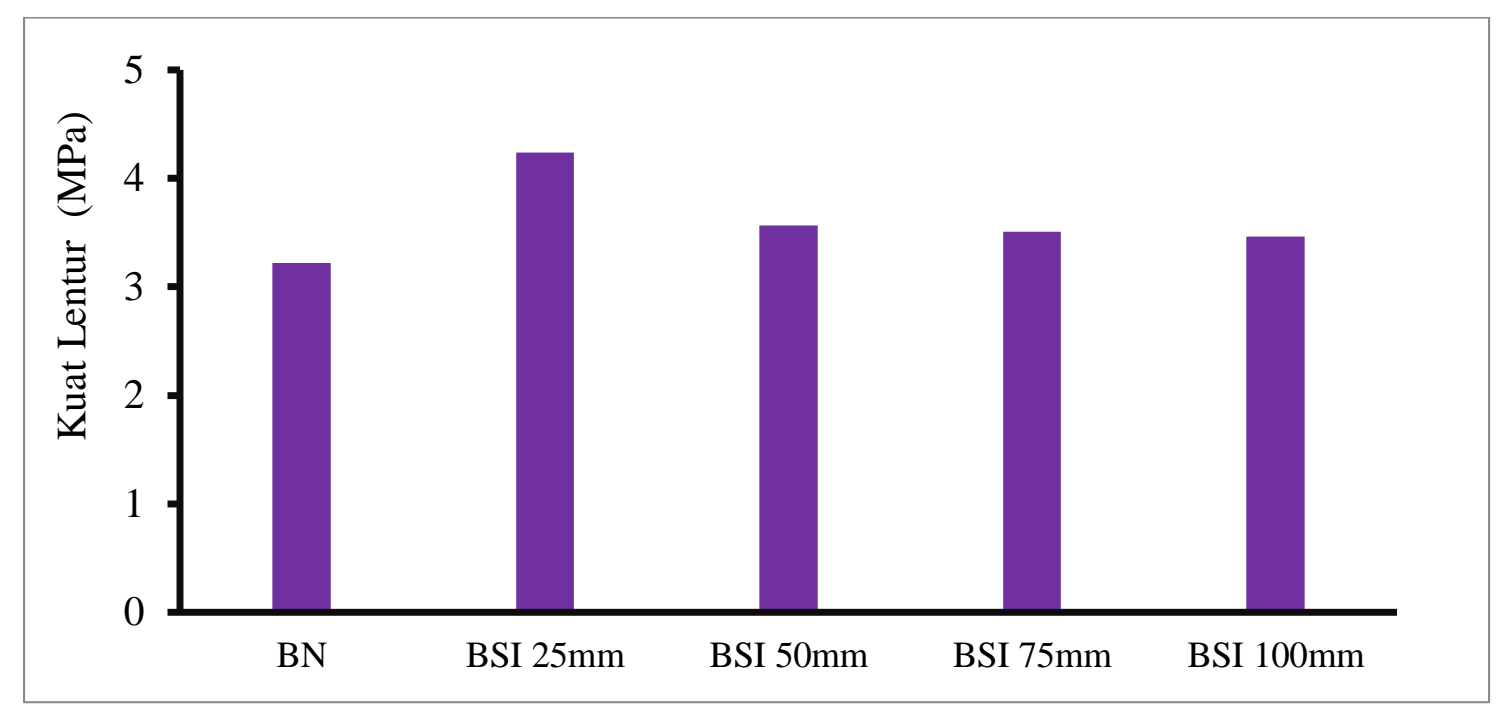

Gambar 3. Nilai Kuat Lentur Beton Serat ljuk

Gambar 3 menunjukan hubungan kuat lentur dan variasi panjang serat ijuk. Beton serat yang menggunakan serat ijuk yang divariasikan berdasarkan panjang serat $25 \mathrm{~mm}, 50 \mathrm{~mm}, 75 \mathrm{~mm}, 100 \mathrm{~mm}$ diperoleh kuat lentur beton berturut-turut sebesar 4,24 MPa ; 3,56 MPa ; 3,51 MPa ; dan 3,46 MPa. Kuat tarik lentur dengan adanya serat yang ditambahakan pada beton yang terendam air laut dibandingkan dengan beton normal tampa serat dan terendam air tawar. Semakin panjang serat maka semakin rendah kuat tarik lenturnya. Hasil kuat lentur tertinggi yang diperoleh sebesar 4,24 MPa dengan panjang serat $25 \mathrm{~mm}$.

\section{Panjang Serat ljuk Yang Optimum}

Serat ijuk yang ditambahkan pada beton yang terendam air laut memiliki pengaruh terhadap nilai sifat mekanik beton. Sebagaimana yang telah dibahas sebelumnya bahwa semakin panjnag serat ijuk maka semakin menurun kuat tekan, kuat lentur dan kuat tarik belahnya. Rekapitulasi hasil pengujian kekuatan beton ditunjukkan pada Tabel 4 .

Tabel 4. Kuat Tekan, Kuat tarik Belah dan Kuat Lentur pada Beton Serat ljuk

\begin{tabular}{cccc}
\hline Nama Sampel & Kuat Tekan (MPa) & Kuat Tarik Belah (MPa) & $\begin{array}{c}\text { Kuat Lentur } \\
(\mathbf{M P a})\end{array}$ \\
\hline BSI $25 \mathrm{~mm}$ & 28,87 & 4,56 & 4,24 \\
BSI $50 \mathrm{~mm}$ & 25,48 & 3,77 & 3,56 \\
BSI $75 \mathrm{~mm}$ & 25,05 & 3,61 & 3,51 \\
BSI $100 \mathrm{~mm}$ & 24,63 & 3,50 & 3,46 \\
\hline
\end{tabular}

Tabel 4 memperlihatkan rekapitulasi hasil pengujian sifat mekanik variasi panjang serat ijuk memiliki sifat mekanik yang berbeda-beda walaupun penambahan serat yang digunakan sama yaitu $4 \%$ dari berat semen. Dapat dilihat pula bahwa dengan memvariasikan panjang serat dapat mempengaruhi nilai sifat mekanik beton serat. Dimana semakin panjang serat ijuk yang digunakan maka 
semakin menurun nilai sifat mekaniknya. Panjang serat ijuk yang optimum untuk adukan beton diperoleh berdasarkan hasil pengujian sifat mekanik beton serat adalah $25 \mathrm{~mm}$. Nilai kuat tekan, kuat tarik belah dan kuat lentur pada beton yang ditambahkan serat ijuk dengan panjang serat $25 \mathrm{~mm}$ berturut-turut sebesar 28,87 MPa; 4,56 MPa; dan 4,24 MPa.

\section{KESIMPULAN}

Nilai kuat tekan, kuat tarik belah dan kuat lentur pada beton serat serat (25 $\mathrm{mm}, 50 \mathrm{~mm}, 75 \mathrm{~mm}$, dan $100 \mathrm{~mm}$ ) yang terendam air laut yang menggunakan serat ijuk yakni nilai kuat tekan berturut-turut sebesar 28,87 MPa; 25,48 MPa ; 25,05 MPa ; dan 24,63 MPa; untuk nilai kuat tarik belah beton serat ijuk berturut-turut sebesar 4,56 MPa ; 3,77 MPa ; 3,61 MPa ; dan 3,50 MPa; dan untuk kuat lentur beton berturut-turut sebesar 4,24 MPa ; 3,56 MPa ; 3,51 MPa ; dan 3,46 MPa. Semakin panjang serat ijuk yang digunakan pada beton maka sifat mekaniknya semakin menurun. Beton serat yang terendam air laut lebih tinggi nilai sifat mekaniknya dibandingkan beton normal. Panjang serat ijuk yang optimum untuk campuran beton yang diperoleh berdasarkan hasil pengujian sifat mekanik beton serat adalah $25 \mathrm{~mm}$. Efek panjang serat ijuk terhadap campuran beton dapat menurunkan nilai sifat mekanik (kuat tekan, kuat tarik belah dan kuat lentur) beton serat yang terendam air laut. Dimana semakin panjang serat ijuk yang digunakan maka semakin menurun nilai sifat mekaniknya.

\section{DAFTAR PUSTAKA}

Committee 544-ACI 544.1R-96 (2002). State-of-the-Art Report on Fiber Reinforced Concrete.

Darul, Syahroni dan Edison B (2014). Kajian Pengaruh Serat ljuk Terhadap Kuat Tarik Belah Beton K-175, e-Journal Mahasiswa Teknik, Vol 1, no. 1, Fakultas Teknik, Universitas Pasir Pengairan.

Doni Hermanto, Supardi, dan Edy Purwanto. (2014). Kuat Tekan Batako Dengan Variasi Bahan Tambah Serat Ijuk, e-Jurnal Matriks Teknik Sipil, Vol 2, no. 3, hal : 491-497, Prodi Teknik Sipil, FT UNS Surakarta.

Erniati dan Muhammad Wihardi Tjaronge (2016). Microstructure Self Compacting Concrete, Leutikaprio, Yogyakarta.

Erniati, M.W Tjaronge, R. Djamaluddin, V. Sampebulu (2014). Microstructure Characteristics of Self Compacting Concrete using Sea Water, International Journal of Applied Engineering Research, Vol 22, pg. 18087-18095

Erniati, M.W Tjaronge, R. Djamaluddin, V. Sampebulu (2015). Compressive Strength and Slump Flow of Self Compacting Concrete Uses Fresh Water and Sea Water, ARPN Journal of Engineering and Applied Sciences, Vol 6 no. 10, 23732377.

Hidayat dan Rizqi Rizaldi (2011). Rancang Bangun Alat Pemisah Garam Dan Air Tawar Dengan Menggunakan Energi Matahari, Skripsi. Dep. Ilmu \& Teknologi Kelautan, Fakultas Perikanan Dan Ilmu Kelautan, Institut Pertanian Bogor, Bogor.

J.G.M. Gregor (1997). Reinforced Concrete Mechanicsand Designs, Prentice Hall, Inc.Upper Saddle River, Third Edition, New Jersey. 
Mikael Wora dan Fransiskus Xaverius Ndale (2018). Pengaruh Penambahan Serat ljuk Dapat Meningkatkan Kuat Tarik pada Beton Mutu Normal, Jurnal IPTEK, Vol 22, No. 2, hal 51-58, Desember 2018

Mohamed A. Ismail and Huzaifah Bin Hasyim (2008). Palm oil Fiber Concrete. Departemen of Structures and Materials, Faculty of Civil Engineering, University Technology, Malaysia.

Mudji Suhardiman (2011). Kajian Pengaruh Penambahan Serat Bambu Ori Terhadap Kuat Tekan dan Kuat Tarik Beton, Jurnal Teknik Vol. 1 No. 2, Oktober 2011

Mulyono, T. (2004). Teknologi Beton, CV. Penerbit Andi Publishing, Jogjakarta.

Neville dan Brooks (2010). Concrete Technology, Second Edition, Prentice Hall.

Randing (1995). Pengaruh penambahan serat ijuk pada pembuatan genteng beton, Jurnal Penelitian Permukian volume 11, No. 1, Puslitbangkim, Bandung.

SII - 0052 - 80 (1981). Mutu dan Cara Uji Agregat Beton.

Standar Nasional Indonesia (SNI) 2491 (2014). Metode Uji Kekuatan Tarik Belah Spesimen Beton Silinder. Badan Standarisasi Nasional, Jakarta

Standar Nasional Indonesia (SNI) 4431 (2011). Cara Uji Kuat Lentur Normal Dengan Dua Titik Pembebanan, Badan Standarisasi Nasional, Jakarta

Standar Nasional Indonesia 1974-2011. Cara Uji Kuat Tekan Beton Dengan Benda Uji Silinder, Badan Standarisasi Nasional (2011), Jakarta

Tjokrodimuljo K (1996). Teknologi Beton, Jurusan Teknik Sipil, Fakultas Teknik, UGM, Yogyakarta.

Yuwono, S (1994). Pengaruh penambahan serat ijuk dan serabut kelapa bahan bangunan genteng dan panel limbah PDAM: dinding, Jurnal Penelitian Permukian volume 10, No.6, Puslitbangkim, 1994, Bandung. 